\title{
Journal of Psychiatry and Cognitive Behavior
}

\section{Seven Hundred Crimes of Violence by 80 Boys: A Follow-Up Study of Childhood Aggressiveness}

\author{
Arne Dalteg, Sten Levander* \\ Department of Criminology, Faculty of Health and Welfare, Malmö University, Sweden
}

"Corresponding author: Sten Levander, Department of Criminology, Faculty of Health and Welfare, Malmö University, Nordenskiöldsgatan 1, 21119 Malmö, SE 205 06, Sweden. Tel: +46406657000; Email: sten@eurocog.eu

Citation: Dalteg A, Levander S (2017) Seven Hundred Crimes of Violence by 80 Boys: A Follow-Up Study of Childhood Aggressiveness. J Psychiatry Cogn Behav 2: 133. DOI: 10.29011/2574-7762.000033

Received Date: 04 November, 2017; Accepted Date: 12 December, 2017; Published Date: 20 December, 2017

\begin{abstract}
DSM-III defined an Aggressive subtype of Conduct disoder; removed from later DSM-versions. The aim of this study was to analyse correlates of aggression and its predictive power from childhood up to age 57 in very advanced juvenile delinquents. 80 boys entered the study 1975-76 while being cared for in a national (last resort) Juvenile Correction (JC) school. All boys had serious behavioural problems with onset before age 12. Scores on a 4-point Childhood Aggression Behaviour (CAB) scale were bimodal. Aggression was retrospectively associated with poor socio-economic conditions and school problems, predicted violent crimes and discipline problems during JC, and violent crimes but not other crimes or social outcome in adulthood (at age 30). Mortality was high, Relative Risk was 8 at age 30 and 44\% were dead at age 57 (20 lost years of life). The predictive power of CAB for future crimes of violence suggests that the Aggressive subtype of DSM-III CD maybe should be reintroduced.
\end{abstract}

Keywords: ADHD; Aggression; Conduct Disorder; Juvenile Delinquency; Mortality; Violent Crimes

\section{Introduction}

\section{General Introduction}

The number of children who have committed acts of violence has increased in the Western world over many years [1-3]. Crimes of violence and other aggressive acts by children and juveniles have become a major problem for instance in the school systems. The stability of individual aggression and the predictive value of early aggressiveness for later problems have been studied by several authors. Whatever its causes, aggression can be viewed as a persistent trait that interacts with situation variables but possesses substantial cross-situation constancy, as well as cross-generation stability [4-6]. Thus, aggressive juveniles tend to become aggressive adults, unless we are able to prevent that. There are good reasons to intervene early - such interventions can be assumed to be more effective. Reducing the overall level of violence is certainly motivated, for instance by the fact that violent crimes are the ones that are most often referred to as the source of fear of crimes in local domiciles.

The distribution of crimes in the population is highly skewed. Approximately 2 percent of all individuals $(3.6 \%$ men and $0.4 \%$ women) are responsible for more than 50 percent of all crimes. Most of them are early starters, i.e., they embark on a criminal career before age 15 [7]. It is a reasonable assumption that early onset aggression problems predict violent criminality in adulthood, as well as later mental health problems, social dysfunction and early death.

For the most serious form of childhood aggression problems, underaged killers, there are surprisingly few scientific studies. In their literature review from 1981, Solway and co-workers [8] identified five relevant studies, all retrospective and with many scientific weaknesses [9]. Neurological abnormalities have been described in juvenile murderers as well as in aggression-prone juvenile correction boys [10-14] have emphasised the presence of major neurological impairment in the juvenile murderer population as evidenced by histories of severe head injury, EEG abnormalities, present and past seizure disorders, abnormal head circumferences, deficits on neuropsychological testing and soft neurological signs [15-17]. Many of the aggressive crimes are committed while the juvenile perpetrator is under the influence of alcohol or drugs $[18,19]$. A 1987 U.S. Department of Justice study found that $43 \%$ of their group of juvenile murderers were intoxicated by one or another psychoactive compound at the time of the crime. In a group of subjects with neurological abnormalities one might expect a higher frequency of deviant drug reactions [20]. 


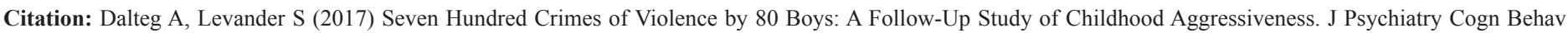
2: 133. DOI: $10.29011 / 2574-7762.000033$

\section{The Swedish National Perspective and This Study}

During 1940-82 the contemporary Juvenile Correction (JC) system in Sweden was modelled on the English Borstal school system. In the following text the Swedish juvenile correction units are denoted JC schools. Approximately 1000-1500 individuals (from a population of 7 million) were cared for in approximately 20 separate institutions spread out over the country. In spite of excellent research facilities, very few studies were performed. A screening of JC subjects by Blomberg \& Grunewald [21] suggested that $25 \%$ of the boys and $15 \%$ of the girls had or could be suspected to have a brain lesion. Some of the juveniles were described as extremely violent. This number grew from $5 \%$ during the 50 ies [22] to $10-15 \%$ during the 60 ies [23]. The situation was probably much worse during the 70ies, i.e., at the time of the data collection of the present study (1975-76).

The mortality rate among the juveniles during the 70 s was $1.1 \% /$ year. The highest mortality rate was among young girls (almost $2 \% /$ year). In general, the mortality rate was 34 times higher compared to demographic data and 86 times higher for young girls.

Our data were collected at one of the twenty Swedish JC schools, the one with the most seriously disturbed boys from all parts of the country (the other schools had local catchment areas). During the decade of data collection (1970s) physical aggression and violence became common among juveniles and a dominant reason for referral to JC treatment. Swedish JC schools were closed in 1982.

\section{Aims of the Study}

The main aim of this report was to analyse the long-term consequences of childhood aggression as a complicating factor to Conduct Disorder (CD) problems. We have previously reported on a similar issue: Attention Deficit Hyperactivity Disorder (ADHD) and CD [24]. Since there were no strong relations between aggression and ADHD in that study, it opened for a non-confounded analysis of early onset aggression and $\mathrm{CD}$. In a retrospective and concurrent perspective, we were interested in possible family environmental determinants of childhood aggressiveness, and in the early manifestations of these problems. In the prospective perspective we were interested in the volume and characteristics of criminality from age 15 and onwards, particularly if aggressiveness was specifically associated with crimes of violence and with a high degree of criminal versatility. Furthermore we were interested in whether aggressive subjects had more psychiatric problems/more drug addiction, were less well adjusted in terms of social functioning in adult life, and instances of early death.

\section{Method}

\section{Subjects}

The data of the present report were obtained by our team in 1975 to 1976 at a national JC institution for serious, recidivist youth offenders, admitted before age 16, the Lövsta School (LS). Boys were referred to compulsory treatment from all regions of Sweden. The admission age varied from 12 to 16 years. The delinquents could remain under the jurisdiction of the institution until age 20 according to the contemporary legislation.

During 1976, 80 boys were treated at the institution, including four boys who were referred for assessment rather than for long-term treatment. Our sample represents approximately $10 \%$ of all Swedish JC boys in 1976, and at least $50 \%$ of those admitted before age 16 , with a bias towards more serious cases. The years of admission and discharge of the subjects ranged from 1969 to 1982. Average age at inclusion time (1976) was 16.1 years (range 13 to 19). All subjects fulfilled DSM III-R criteria for Conduct Disorder (CD), and represent approximately 0.04 percent of the boys of each year cohort in Sweden. In the following text they are denoted Advanced Juvenile Delinquents (AJD).

\section{Data Collection}

The retrospective data set was scored from the extensive files of the 80 subjects. For 42 subjects, an extensive data set was available (including psychophysiology and psycho-endocrinology); for 38 a basic data set. The files provided detailed information on childhood psychosocial background, somatic and psychiatric history, and criminality up to referral to the LS school.

The concurrent data set covers data from the subjects' treatment period at the LS school up to 1980, and reflects furloughs, probation periods, placements in closed cottages and temporary seclusion from the peer group, escapes and criminality. Aggressive acts against staff were recorded separately.

Follow-up data were first obtained when all subjects were 21 years of age or more through various official registers, e.g. military data and data on drivers' licences, social security data bases, and the National Police Register. Further data were obtained in a personal interview performed at least 8 years after JC discharge. A new set of register data was collected in 1995, when all subjects were age 25 or more. Finally, register data on mortality were collected in 2016, i.e. when the mean age of the participants was 56 .

\section{Analyses of Criminality}

The criminal records were analysed for three-time periods:

- From onset of criminality (6 years for the youngest) up to but not including age 15.

- $\quad$ Age 15 to 17 and

- From age 18 into adulthood (average age at follow-up 28.6, range 25 to 32 ).

These intervals were chosen to match the contemporary Swedish legislation of no criminal responsibility before age 15 , and 


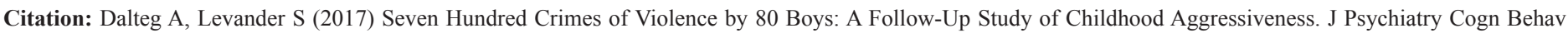
2: 133. DOI: $10.29011 / 2574-7762.000033$

JC school as the "normal" sanction between 15 and 18 years of age. After age 18, AJDs were sentenced to prison for serious crimes. Data on criminality were scored from the Swedish Police register from age 15; childhood criminal data were scored from the social authorities' investigations before JC referral, and from the LS files. In addition, three items from the Psychopathy checklist [25] pertaining to criminality were scored on the basis of the extensive file data:

- Criminal versatility (CV, Item 20).

- Revocation of crime under JC/conditional release (RC, Item 19).

- Criminal negligence (CN, Item 11) of the PCL-R.

Furthermore, two new variables were constructed reflecting Cumulated crimes of violence (murder, arson, sexual crimes, robbery, assault, threat, criminal possession of weapon, 'causing danger to other people', 'unlawful entering of people's homes', and torturing of animals; and Age at termination of criminality (12 months without registered criminality while not in custody).

\section{Ratings of Aggressiveness}

Several different ratings (self-assessment, staff - and psychiatric ratings) of aggressiveness were obtained for a subset of the subjects $(\mathrm{N}=42)$. There were substantial inter-correlations among psychiatric ratings and staff ratings of different parameters of aggressive behaviour for this data set. There were also significant correlations between self-rated physical aggression and the corresponding $\operatorname{staff}(\mathrm{r}=.55)$ and psychiatric $(\mathrm{r}=.37)$ ratings 1980 [26]. One of the current authors (AD) performed ratings of childhood aggressive behaviour $(\mathrm{CAB}$, the main independent variable of this report) for all subjects $(\mathrm{N}=80)$ using social case records only (for details see Appendix) and was blinded as regards the psychiatric and other ratings. The correlation between $\mathrm{CAB}$ and the psychiatric ratings on the subsample was adequate (median $r=.60$ ). Thus, the CAB ratings can be assumed to reflect salient and valid information. On the bases of the social case records further global ratings on three-step scales of the following variables concerning the subject's childhood conditions were performed by one rater (AD): a) stability of upbringing; b) socio-economic level; c) psychological background; d) childhood aggressiveness; e) hyperactivity; and f) parent's/sibling's psychosocial history [24].

\begin{tabular}{|c|c|}
\hline \multicolumn{2}{|c|}{ Rating scale of childhood aggressiveness from social case records } \\
\hline 0 & No notes of particular aggressiveness in the files. \\
\hline 1 & $\begin{array}{c}\text { Aggressiveness to the degree that class-mates and younger } \\
\text { children were afraid of the boy. Frequent outbursts of } \\
\text { aggressiveness against caretaker. }\end{array}$ \\
\hline 2 & $\begin{array}{c}\text { Aggressiveness with substantial difficulties for upbringing; } \\
\text { specific actions taken because of problems in grade school, } \\
\text { for instance expelled from school due to dangerousness } \\
\text { to classmates or younger children. Regularly aggressive } \\
\text { outbursts when frustrated. }\end{array}$ \\
\hline
\end{tabular}

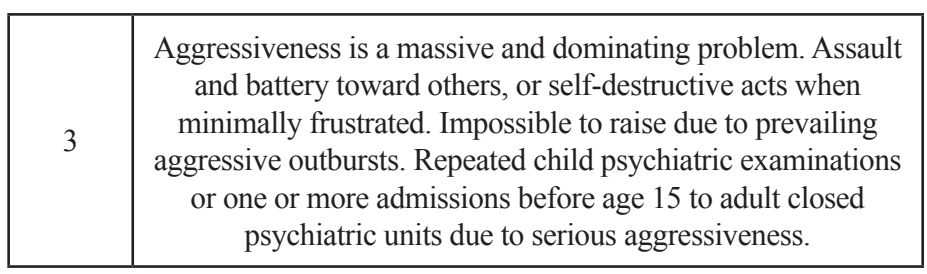

\section{Appendix}

Information about abuse (alcohol, solvents and drugs) and school problems was scored by AD. Discharge from JC care was granted by the school board according to four law paragraphs. The discharge paragraph can be viewed as a global rating of the success or failure of the period of JC treatment of an individual. The reasons for discharge were: (1) "Purpose of treatment fulfilled"; (2) "Reached upper age limit"; (3) "Transferred to mental hospital"; (4) "Sentenced to prison". Each subject was assigned a score according to the discharge paragraph from the JC school.

The Custody variable refers to the total number of days spent in imprisonment or on furloughs from prison, and as inpatient in psychiatric institutions.

The number of days of illness during the 21st year of life was obtained from the National Insurance Register: The type of illness was classified on a 12-point scale ranging from minor somatic illness to chronic psychotic disorder.

\section{Treatment of Data}

\section{Subgroupings based on Aggressiveness}

In the following analyses, the 80 LS boys were sub-grouped into four groups reflecting various degrees of observed and recorded childhood aggressiveness (the CAB scale, see Appendix). 40 boys (50\%) were assigned score 0 (non-aggressive, AGG0). 24 (30\%) highly aggressive boys were assigned score 3 (AGG3). Score 1 and 2 were each assigned to eight boys (10\%). Thus, the distribution was bimodal in spite of a linear increase in the described aggression characteristics of the 4-point scale.

\section{Statistical Analyses}

Covariations between aggressiveness $(\mathrm{CAB})$ and the other variables were analysed by Kendall's tau, group mean differences by one-way ANOVAS for the four groups, or by t-tests for subjects with and without aggressiveness (AGG0 vs. AGG1+AGG2+AGG3). The Scheffee test with significance level .05 was chosen for post hoc analyses of multiple subgroup comparisons. CAB scores were analysed in relation to (1) Childhood psychosocial data, school data and criminality data; (2) Concurrent behaviour problems and criminality while under JC care; (3) Prospective follow-up data; (4) Life-time criminality (up to age 35) and (5) mortality. 


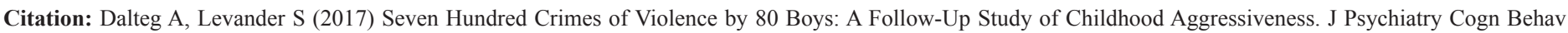
2: 133. DOI: $10.29011 / 2574-7762.000033$

\section{Missing data}

Information on the subject's biological parents were missing for $18 \%$ of the subjects (mothers $4 \%$, fathers $14 \%$ ). The missing data was evenly distributed among the aggressive subgroups. In the analyses of JC data, four subjects who were staying only briefly at the institution were excluded. Some of these subjects were aggressive, and are included in relevant analyses. Post-JC crimes up to the first follow-up at 21 are missing for three subjects due to their early death (records are cancelled from the Police register when a person dies and after ten years of no new crimes). Another five subjects died during the period up to the 1995 follow-up. For those subjects we have almost complete crime data sets because we collected repeated data sets from the Police register.

\section{Interpretation of Correlation Coefficients}

Inordertofacilitatetheinterpretationofcorrelationcoefficientsall variableswerescoredsothatahighnumericalvaluereflectsdisadvantage, greater seriousness or deviancy, and a more negative outcome.

\section{Results}

\section{General Background of Delinquent Subjects}

The average birth year of the AJD's was 1959 (range 1956 to 1963). The subjects were recruited from all over Sweden. Metropolitan areas dominated. Immigrants were strongly over-represented, 30\% $(\mathrm{N}=24)$ compared to the average contemporary immigrant ratio of less than $7 \%$ (at least one parent having immigrated). Immigrants and geographical areas were evenly distributed among the four aggression groups.

\section{Data Before Referral to JC}

\section{Family and Psychosocial Background}

Approximately half of the biological parents were psychosocially maladjusted, i.e. had been treated for psychiatric disorders, sentenced for crimes, or registered for alcoholism. 84\% of the fathers and $62 \%$ of the mothers were socially dysfunctional. There was a strong dominance of low social class among the families and the number of children per family was high; an average between 4 and 5 (range 1 to 8 ) vs. slightly less than two kids per family in Sweden at that time.

Aggressiveness $(\mathrm{CAB})$ co-varied with poor socio-economic conditions during early $(\mathrm{p}<.05)$ and late childhood $(\mathrm{p}<.10)$, with number of placements in child psychiatric units $(\mathrm{p}<.001)$ and time in institutions (other than JCs) $(\mathrm{p}<.05)$. The highest number of delinquent siblings was found among the AGG3 subjects $(\mathrm{p}<.05)$. Non-aggressiveness (AGG0) co-varied with parents' divorce $(\mathrm{p}<.05)$ and with poor living quality $(\mathrm{p}<.05)$. Subgroup analyses confirmed the general pattern. AGG3 had the highest number of placements in child psychiatric units, AGG0 and AGG1 the lowest $(\mathrm{p}<.001)$.

\section{School Data}

The majority of the subjects were referred to special teaching programs within the elementary school from early years. Fifteen $(20 \%)$ were expelled from the ordinary school system at a median age of 12 (range 6 to 15) due to aggressive behaviours against teachers and peers. None of the subjects completed elementary school (9 years) in their home community. Correlations were calculated for the following variables: ADHD symptoms, Special class referral, Underachievement, Truancy, Discipline problems, Mobbing, and Being expelled, and for two-time periods: Grade 1-6 and 7-9. All correlations except one were significant. Cronbach's alpha for the seven variables of Grade 1-6 was 0.59 and for Grade 7-9 it was 0.60. A factor analysis suggested two correlated factors. The strongest factor comprised five variables. Underachievement and Hyperactivity formed the second factor. Thus, one type of school problems tended to be associated with other school problems.

\section{Delinquency, Abuse and Behaviour Problems Before JC}

All subjects had a criminal record before JC referral. Abuse problems (solvents, alcohol and/or drugs) were noted for 91\%. Alcohol abuse was present in 65\%, solvent abuse in $65 \%$, and drug abuse (mostly cannabis) in $45 \%$. The frequency of salient symptoms/ behaviours is given in Table 1. There were no significant associations between aggressiveness and the subjects' psychiatric or abuse symptoms/ problems.

\begin{tabular}{|c|c|c|c|}
\hline Symptom & Rate & Symptom & Rate \\
\hline Criminality: & 1 & Concentration difficulties & 0.62 \\
\hline $\begin{array}{c}\text { property } \\
\text { crimes }\end{array}$ & 1 & Hyperactivity & 0.53 \\
\hline $\begin{array}{c}\text { car/vehicle } \\
\text { thefts }\end{array}$ & 0.69 & Aggressiveness & 0.52 \\
\hline $\begin{array}{c}\text { crimes of } \\
\text { violence }\end{array}$ & 0.4 & Dyslexia & 0.41 \\
\hline $\begin{array}{c}\text { armed } \\
\text { robbery }\end{array}$ & 0.11 & Anxiety & 0.29 \\
\hline $\begin{array}{c}\text { assault } \\
\text { cruelty to }\end{array}$ & 0.33 & Psychosomatic symptoms & 0.27 \\
\hline Abimals & 0.01 & Mobbing & 0.19 \\
\hline alcohol & 0.69 & Stuttering & 0.04 \\
\hline solvents & 0.65 & Depression & 0.1 \\
\hline \begin{tabular}{c} 
drugs \\
\hline
\end{tabular} & 0.53 & Shyness & 0.06 \\
\hline
\end{tabular}


Citation: Dalteg A, Levander S (2017) Seven Hundred Crimes of Violence by 80 Boys: A Follow-Up Study of Childhood Aggressiveness. J Psychiatry Cogn Behav 2: 133. DOI: $10.29011 / 2574-7762.000033$

\begin{tabular}{|c|c|c|c|}
\hline Vagrancy & 0.9 & Tics & 0.03 \\
\hline $\begin{array}{c}\text { Property } \\
\text { damage }\end{array}$ & 0.75 & Phobias & 0.03 \\
\hline
\end{tabular}

Table 1: Frequency of symptoms of 80 AJD boys before JC referral.

In the $\mathrm{N}=42$ subgroup, an extensive data set was collected that contained more detailed and reliable psychiatric data [26,27]. Analyses of this subgroup which contained most of the severe cases (more in-patient than out-patient treatments) yielded another pattern. Aggression (CAB) covaried with ratings of hyperactivity: $\mathrm{p}<.001$; with poor concentration: $\mathrm{p}<.01$ ); truancy: $\mathrm{p}<.05$; assault: $\mathrm{p}<.01$; armed robbery: $\mathrm{p}<.01$; physical and verbal fights: $\mathrm{p}<.01$; assertiveness: $\mathrm{p}<.05$; somatic anxiety: $\mathrm{p}<.05$; remorse: $\mathrm{p}<.001$; and cognitive slippage: $\mathrm{p}<.01$.

The total number of crimes before age 15 was 2824 (mean 23.2 range $7-212$ ). $3 \%$ of these crimes were crimes of violence (mean 1.3, range 0-9). As shown in Table 2, AGG3 had the highest ratio of crimes of violence. Aggressiveness (CAB) co-varied with assaults $(\mathrm{p}<.001)$, armed robberies $(p>.01)$, illegal possession of weapon $(p<.05)$ and cumulated crimes of violence $(\mathrm{p}<.05)$.

\section{Data during JC}

The present sample of AJDs was homogenous in at least three important ways. (1) All (100\%) were cleared for placement in locked units by the National Board of Social Welfare (compared to $40 \%$ for the contemporary JC population); (2) All met retrospectively the DSM III-R criteria for Conduct Disorder (CD); and (3) All met the PCL-R item 11 score 2 criterion of Early Behaviour Problems i.e. serious behavioural problems with onset before age 12 .

\section{JC Jurisdiction}

Mean age at JC school admission was 14.5 (range 12.1 to 15.8).
The average number of days under JC jurisdiction was 1.482 (range 20 to 2.623$)$. Twelve (15\%) of the subjects were transferred from other JC schools to LS due to disciplinary problems (mainly violence against staff, escapes and other serious non-compliant behaviour). They tended to be more aggressive than the average subject $(\mathrm{p}<.10)$. There were no associations between aggressiveness, age of admission and number of treatment days.

Escapes from JCs were common in the 70ies, and averaged 20 in the present group (range 0 to 72). The number of days on escape averaged 100 (range 0 to 337). Escapes were generally terminated by police capture in association with new crimes. Voluntary returns averaged 1 in 20. The AGG3 group had the lowest number of escape days $(\mathrm{p}<.01)$.

Discipline problems could be handled by time-limited placements in locked units and short-term (48 hours) seclusion from the peer group. Placements in locked units averaged 9 (range 0 to 39) and number of days in these units averaged 117 per individual (range 0 to 526). Seclusion averaged 2 (range 0 to 13) days. Aggressiveness (CAB) tended to be associated with number of days in locked units $(\mathrm{p}<.10)$ but not with seclusion.

During 1976, $16(20 \%)$ of the subjects were reported to the JC board at 32 occasions for violence against the staff $(50 \%$ of the occasions during placements in closed cottage; $25 \%$ were directed against female staff reflecting the actual staff sex ratio). Aggressiveness $(\mathrm{CAB})$ covaried with total number of violence against staff $(\mathrm{p}<.01)$; during placement in open cottages $(p<.05)$ as well as during parole time $(\mathrm{p}<.10)$.

The total number of prosecuted crimes during the JC period (4 years) was 5,685, averaging 77.3 crimes per boy (range 0 - 334). The cumulated crimes of violence represented $2 \%$ of all crimes and averaged 2.1 (range 0-13, Table 2). Aggression (CAB) co-varied with cumulated crimes of violence $(\mathrm{p}<.05)$.

\begin{tabular}{|c|c|c|c|c|c|c|}
\hline & \multicolumn{2}{|c|}{ Childhood } & \multicolumn{2}{c|}{ Adulthood } & \multicolumn{2}{c|}{ Life-time } \\
\hline & \multicolumn{2}{|c|}{ Age $6-14$} & \multicolumn{2}{c|}{ Age 19 - 30 } & \multicolumn{2}{c|}{ Age $6-30$} \\
\hline & Total & Viol. & Total & Viol. & Viol. \\
\hline & M SD & M \pm SD & M SD & M \pm DD & M $\pm S D$ & M SD \\
\hline AGG0 & $36 \pm 25$ & $2.3 \pm 2.3$ & $47 \pm 29$ & $4.1 \pm 5.7$ & $160 \pm 99$ & $6.6 \pm 7.1$ \\
\hline AGG1 & $38 \pm 17$ & $3.6 \pm 1.5$ & $36 \pm 31$ & $3.5 \pm 3.2$ & $160 \pm 130$ & $4.9 \pm 3.7$ \\
\hline AGG2 & $37 \pm 31$ & $2.5 \pm 1.5$ & $59 \pm 50$ & $3.9 \pm 5.6$ & $173 \pm 179$ & $6.3 \pm 7.1$ \\
\hline AGG3 & $39 \pm 41$ & $3.8 \pm 3.1$ & $57 \pm 52$ & $6.5 \pm 6.3$ & $183 \pm 140$ & $12.1 \pm 9$ \\
\hline Mean & $37 \pm 30$ & $2.9 \pm 2.5$ & $50 \pm 39$ & $4.8 \pm 5.7$ & $168 \pm 122$ & $8.1 \pm 7.7$ \\
\hline
\end{tabular}

Table 2: Total number of crimes and crimes of violence during three life periods, and cumulated data for four groups of subjects (AGG0 to AGG3) according to rated childhood aggressiveness. 


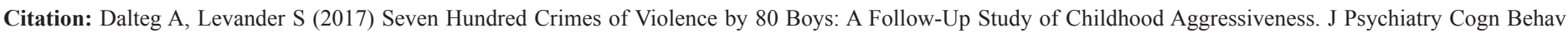
2: 133. DOI: $10.29011 / 2574-7762.000033$

Mean age at JC discharge was 18.8 (range 15.7 to 20.0). Sixteen boys $(20 \%)$ were discharged because "the purpose of treatment was fulfilled"; 23 (29\%) "reached age 20"; 4 (5\%) were certified and transferred to psychiatric units; and 32 (40\%) were sentenced to prison. One subject died during LS time. Aggressiveness (CAB) co-varied with a 'worse' discharge paragraph $\left(\mathrm{X}^{2}(12)=23.0 \mathrm{p}<.05\right)$, and with being transferred to psychiatric units $\left(\mathrm{X}^{2}(1)=4.32, \mathrm{p}<.05\right)$. Aggressiveness did not co-vary with discharge age.

\section{Follow-up Data}

\section{The Subjects' 21st Year of Life}

Overall, the subjects spent $47 \%$ of this year in custody (range $0 \%$ to $100 \%$ ). Data from the National Health Insurance office suggested that about half (52\%) of the subjects had some kind of employment and income. Their average illness rate was 54 days (range 0 to 365). Psychosomatic lower back pain accounted for the highest number of these days (19 days). The second most common group of diagnoses reflected psychotic illness (15 days); the third one minor accidents.

Aggressiveness (CAB) co-varied with being in custody $(\mathrm{p}<.05)$, and tended to co-vary with a diagnosis of psychotic illness $(\mathrm{p}<.10)$. Subgroup analyses showed that AGG3 contained all the psychotic subjects $(\mathrm{p}<.05)$, later diagnosed with schizophrenia.

\section{Criminality during age 18-28}

The total number of registered crimes was 3.575 with an average of 50 (range 0 to 170). The share of crimes of violence had increased, from the pre-LS $2 \%$ and the LS time $3 \%$, to $9 \%$ of total number of crimes, with an average of 5 (range 0-26, see Table 2).

Aggressiveness (CAB) co-varied with murder $(\mathrm{p}<.05)$, assaults $(\mathrm{p}<.05)$, threats $(\mathrm{p}<.05)$ property damage $(\mathrm{p}<.01)$; and nonaggressiveness with escapes $(\mathrm{p}<.01)$.

\section{Forensic Psychiatric Assessments}

Twenty-four subjects (30\%) had been assessed once, 14 (18\%) twice, and three (4\%) subjects three times. Aggressiveness (CAB) co-varied with number of forensic examinations $(\mathrm{p}<.01)$.

\section{The Life Situation at Follow-Up 1 (1990)}

Ten (13\%) subjects were dead (all violent deaths: suicide, intoxication or murder). Six ( $8 \%$ ) were certified and in mental units, all with schizophrenia. $36(44 \%)$ were currently serving prison sentences, of whom $14(17 \%)$ were on parole. The remaining 28 $(35 \%)$ were free (Table 3). Aggressiveness (CAB) co-varied with being in prison $\left(\mathrm{X}^{2}(1)=4.01, \mathrm{p}<.05\right)$ but not with being in a mental unit, being on parole or free. Childhood non-aggressiveness was significantly associated with mortality $\left(\mathrm{X}^{2}(1)=4.11, \mathrm{p}<.05\right)$.

\section{Mortality at the 2016 follow-up}

According to a separate register search in 2016 (at an average age of 56), 35 (44\%) of the 80 subjects were now dead. Childhood non-aggressiveness was not significantly associated with long-term mortality.

\begin{tabular}{|c|c|c|c|c|c|c|}
\hline & Dead & Certified & Prison & Parole & Free & Row total \\
\hline AGG0 & 8 & 3 & 7 & 7 & 15 & 40 \\
\hline AGG1 & 0 & 1 & 2 & 2 & 3 & 8 \\
\hline AGG2 & 1 & 1 & 3 & 1 & 2 & 8 \\
\hline AGG3 & 1 & 1 & 10 & 4 & 8 & 24 \\
\hline All & 10 & 6 & 22 & 14 & 28 & 80 \\
\hline Perc. & 12.5 & 7.5 & 27.5 & 17.5 & 35 & 100 \\
\hline
\end{tabular}

Table 3: Summary of the subjects' living conditions at age 25-32.

\section{Analyses Based on Data from Childhood Until Follow-up}

\section{Cumulated Criminality}

The cumulated number of prosecuted crimes from child- to adulthood reached almost 12.000 (11.913), with an average of 163 (range 14 to 558). Cumulated crimes of violence (4\%) averaged 8.3 (range 0 to 34). Aggressiveness (CAB) was significantly associated with assaults $(\mathrm{p}<.01)$, threats $(\mathrm{p}<.05)$, murder $(\mathrm{p}=.06)$ property damage $(\mathrm{p}<.01)$ and cumulated crimes of violence $(\mathrm{p}<.01)$. Subgroup analyses $\left(\mathrm{X}^{2}(3)=24.8, \mathrm{p}<.001\right)$ showed a linearly increasing trend for cumulated crimes of violence from AGG0 to AGG3. Crimes of violence peaked in adulthood (60\% of the total number) whereas property crimes peaked in the mid-teens.

At the time of follow-up 28 subjects were free, 15 AGG0 and 13 AGG1-3. The time without registered criminality in this group averaged 2 years ( 27 vs. 23 months). No significant group differences emerged.

\section{Stability Over Time of Criminality and Aggression}

A large majority of the subjects were registered for their first crime of violence before referral to JC. Among the 15 subjects with no violent crime before JC only two committed crimes of violence until the last follow-up. Stability of crimes over the three periods (childhood, JC, adult) was calculated by Cronbach's alpha. The alpha for overall criminality was $.70(\mathrm{p}<.001)$, and for crimes of violence $.64(p<.001)$. There were significant correlations between overall crimes and crimes of violence within each time period, but not across time periods (Table 4). Thus, for instance, childhood violent crimes predicted childhood overall crimes and crimes of violence in adulthood, but not overall crimes in adulthood.

\begin{tabular}{|c|c|c|c|c|c|c|}
\hline & \multicolumn{3}{|c|}{ Non-violent crimes } & \multicolumn{3}{c|}{ Crimes of violence } \\
\hline CHILDHOOD & child & youth & adult & child & youth & adult \\
\hline $\begin{array}{c}\text { Non-violent } \\
\text { crimes }\end{array}$ & ----- & $<.001$ & $<.001$ & $<.01$ & NS & NS \\
\hline $\begin{array}{c}\text { Crimes of } \\
\text { violence }\end{array}$ & $<.01$ & $<.05$ & NS & ----- & $<.01$ & $<.01$ \\
\hline
\end{tabular}




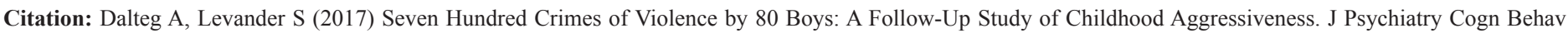
2: 133. DOI: $10.29011 / 2574-7762.000033$

\begin{tabular}{|c|c|c|c|c|c|c|}
\hline $\begin{array}{c}\text { Childhood } \\
\text { aggression }\end{array}$ & NS & NS & NS & $<.05$ & $<.05$ & $<.05$ \\
\hline
\end{tabular}

Table 4: Significance of intercorrelations between childhood measurements of number of crimes, number of crimes of violence, rated childhood aggression and crimes during three-time periods.

\section{Interaction Effects Between ADHD and CAB Scores}

The 80 subjects were redistributed into 16 cells $(4 \times 4)$ representing increasing $\mathrm{CAB}$ as well as ADHD scores [24]. The top left diagonal element comprised subjects with $\mathrm{CAB}$ score 0 and no hyperactivity, the bottom right element subjects with $\mathrm{CAB}$ scores 3 and hyperactivity throughout childhood. There was no interaction effect. Life-time criminality increased along the diagonal as the sum of the separate contributions of aggression and hyperactivity.

\section{Discussion}

The distribution of aggression (CAB) scores among the 80 Advanced Juvenile Delinquents (AJDs) was bimodal in spite of the fact that the anchor point definitions of the scale (see Appendix) represent a linear increase in aggressiveness. According to $\mathrm{CAB}$ the large majority $(80 \%)$ of the subjects had either a substantial or no extra dose of childhood aggression relative to the level of aggression inherent in the Conduct Disorder (CD) diagnosis. Such aggression co-varied with poor psychosocial conditions, whereas Attention Deficit/Hyperactivity Disorder problems (ADHD) were inversely related to these conditions [24]. In contrast, aggression, as well as ADHD, co-varied with school problems and under-achievement by summing. The differential associations for aggression and for ADHD with external criteria suggest different generative mechanisms for these two important co-morbid problems of CD.

It should be noted that almost all of the non-aggressive subjects desisted from crimes of violence throughout childhood, adolescence and early adult ages, in spite of the fact that they were placed in an extremely aggressive environment during a significant time period of their youth. This speaks against such social factors as causes of serious violence.

Clinical factors of relevance may be single or multiple episodes of extreme psychosocial stress during early childhood [28]. The psycho-endocrine data obtained from the comprehensively assessed subset of LS boys [27] suggest that permanent changes in the stress handling system were associated with serious early stress (before age $1)$. This may interact with genetically determined variations in glucocorticoid receptors [29].

In a study of 300 intra-venous drug users with respect to aggression history, the participants could be meaningfully disaggregated into four distinct violent offending classes, among those a non-violent class (24\%) and an early-onset, chronic class $(19 \%)$. Class membership explained a large proportion of the variance of criminality [30].
In a study by Morris and co-workers [31], early (before age 5) onset ODD and CD problems were strongly associated with poor outcome. One issue is if this poor prognosis is contingent on additional problems like ADHD and aggressiveness, and whether there are differential associations between such problems and various types of criminality, abuse and other forms of social dysfunction. This issue was studied using a battery of neuro-cognitive tests in a cohort - and the data suggested that ADHD and CD problems were disentangled [32]. These differences emphasize the importance of examining specific $\mathrm{CD}$ behaviors to better understand the underlying neurodevelopmental mechanisms. The authors also suggest that youth who engage in different levels of physical aggression or theft behaviors may require different preventive and corrective interventions.

In the present study, ratings of childhood aggression co-varied consistently with aggressive crimes and other indices of aggression (for instance violence against staff) throughout the investigated time period, up to age 30 , but not with ADHD symptoms, other crimes and social outcome. It might be noted that all subjects who developed a functional psychosis belonged to the group with the highest rating on the four-point scale of childhood aggression, and that forensic psychiatric evaluations were more common among the aggressive subjects. A delay in maturation may be an explanatory factor for ADHD as well as Conduct disorder and specifically for aggression linked to delayed character maturation. This is a factor which can be addressed in remedial work [33].

Early death (before age 30) was common. Almost all the subjects of the present study who died before age 30 belonged to the low aggression group. Aggression seemed to protect from early death but increased the risk to develop a psychotic disorder. Retrospectively, $\mathrm{ADHD}$ as well as CD, regardless of aggression, is a strong risk factor for schizophrenia [34].

Actual crimes of violence committed before age 12 proved to be a still stronger predictor of future crimes of violence than ratings of childhood aggression. However, in a remedial perspective, ratings of aggression are more promising than early crimes of violence for identifying children who need massive interventions directed against their aggression problems. If we are able to identify risk kids early, and develop more effective treatment methods [35], the great payoff is not until they reach age 20 when crimes of violence start to become a more significant part of the overall criminality. The payoff is potentially large. In our group of subjects, we had one double murderer, two murderers, one subject who at 33 occasions caused serious bodily harm to other people and 24 subjects with more than 10 serious crimes of violence. Add to that the dark number ratio of such crimes and the pay-off can be multiplied by approximately four!

In contrast to the DSM-III CD-diagnosis which included subtypes based on socialisation and aggressiveness, neither the DSMIV-TR version, nor the current DSM-5 version help us to identify 


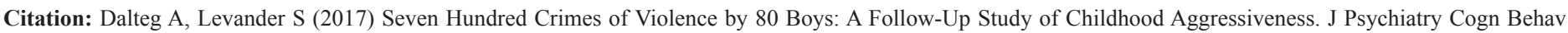
2: 133. DOI: $10.29011 / 2574-7762.000033$

a subtype of highly aggressive CD children. Our findings suggest that a re-introduction of the DSM-IIIR subdivision of CD into nonaggressive and aggressive subtypes may be worthwhile.

In a previous report we demonstrated a relation between retrospective ratings of $\mathrm{ADHD}$ and deviant alcohol reactions associated with crimes of violence [20]. This suggests that it might be particularly important to apply preventive measures against the development of alcohol dependence in the high aggression/ADHD quadrant of AJDs.

The current study covers data on a highly selected group. The strong and clear relationships among various variables that we have obtained in four sets of analyses [24,26,27,36] and the current report) usually do not obtain in research on larger groups of AJDs, where the mechanisms that operate are blurred by more noise. The key finding is that aggression was stable over time, and had a high predictive value for crimes of violence. Another important finding is the independent contributions, without interaction effects, of ADHD and aggression problems to the poor social prognosis of early onset CD problems.

The seriousness of the AJD pattern of symptoms/problems is underlined by the high frequency of psychoses in early adulthood, and the marked increase in mortality. Data from the Swedish longitudinal Metropolitan project (subjects born in 1953) suggests that less than $2 \%$ of the "normal" men but $8 \%$ of drug abusers die before age 30 [37]. For the same material at age 48 around $2 \%$ of normal men were dead [38]. In the group of criminal men 13\% were dead. Similar findings were reported by a Finnish group studying AJDs - at age 35 $11 \%$ had developed a psychotic disorder and $22 \%$ were dead [39]. A citation from this study: The most frequent offenders were nearly 30 times more likely to have died by age 30 than non-offenders.

In a 7-year follow-up study of AJD by Linda Teplin and coworkers [40] they obtained an RR for mortality around 5. Median age at death of Swedish men who were diagnosed with a psychotic illness and released from forensic psychiatric treatment was 51 years [41]. The median life time expectancy in the present group is around 60 , compared to 65 for men in Sweden with schizophrenia but no criminal record [42] and 80 for healthy men. Life time expectancy is shortened by 20 years among advanced juvenile delinquents [43].

Given these findings one should expect that there is a vast scientific literature reporting on the AJD problems in focus for the present study: aggression, crimes of violence and mortality Only little has been published during the last fifteen years. The need for more studies and a better understanding of the violence problem is underlined by Rosell and Sievers (2015) [44], as well as by Erskine, Norman et al (2016) [45]. If we can create effective interventions, the gains are substantial [46].

\section{References}

1. Rivera F \& Grossman D (1996) Prevention of traumatic deaths to children in the United States: how far have we come and where do we need to go?. Pediatrics 97: 791-797.

2. Perry B (1996) The neurobiology of aggression: what makes children violent? The Development or: The Resident and Medical Student Newsletter of the American Academy of Child and Adolescent Psychiatry $3: 4-15$.

3. Ryan G, Miyoshi T, Metzner J, Krugman R, Fryer G (1996) Trends in a national sample of sexually abusive youths. J Am Acad Child Adolesc Psychiatry 35: 17-25.

4. Olweus $D(1979)$ The stability of aggressive reaction patterns in human males: a review. Psychological Bulletin 85: 852-875.

5. Huesmann LR, Eron LD, Lefkowitz MM, Walder LO (1984) Stability of Aggression Over Time and Generations Developmental. Psychology 20: $1120-34$

6. Cadoret RJ, Yates WR, Troughton E, Woodworth G, Stewart MA (1995) Gene-environmental interaction in the genesis of aggressivity and conduct disorders. Arch. Gen. Psychiatry 52: 916-924.

7. Wikström PO, Loeber R (2000) Do disadvantaged neighbourhoods cause well-adjusted children to become adolescent delinquents. A study of male juvenile serious offending, individual risk and protective factors, and neighbourhood context. Criminology 48: 1109-1142.

8. Solway KS, Richardson L, Hayes RJ, Elion VE (1981) Adolescent Murders: Literature Review and Preliminary Research Findings. In (Eds.) Hays, R., Roberts, TK \& Solway, K. Violence and The Violent Individual, 1981. London: MTP Press Limited.

9. Myres WC (1992) What Treatments Do We Have for Children and Adolescents Who Have Killed?. Bull Am Acad Psychiatry Law 20: 47-58.

10. Forssman H, Frey TS (1953) Electroencephalograms of boys with behaviour disorder. Acta Psyciatrica Scandinavica 28: 61-73.

11. Raine A, Brennan P, Mednick SA (1994) Birth Complications Combined With Early Maternal Rejection at Age 1 Predispose to Violent Crime at Age 18 years. Arch Gen Psychiatry 51: 984-988.

12. Lewis DO, Moy E, Jackson LD. (1985) Biopsychosocial characteristics of children who later murder: a prospective study. Am J Psychiatry 142: $1161-1167$.

13. Lewis DO, Pincus JH, Bard B, Richardson E, Princhep LS, et al. (1988) Neuropsychiatric, Psychoeducational and Family Characteristics of 14 Juveniles Condemned to Death in the United States. American Journal of Psychiatry 145: 584-589.

14. Lewis DO, Lovely R, Yeager C (1988) Intrinsic and environmental characteristics of juvenile murderers. J Am Acad Child Adolesc Psychiatry 27: 582-587.

15. Adams KA (1974) The child who murders. Criminal Justice and Behaviour 1: 51-61.

16. Spellacy F (1977) Neuropsychological Differences between Violent and Nonviolent Adolescents. J Clinical Psychology 33: 966-969. 
Citation: Dalteg A, Levander S (2017) Seven Hundred Crimes of Violence by 80 Boys: A Follow-Up Study of Childhood Aggressiveness. J Psychiatry Cogn Behav 2: 133. DOI: $10.29011 / 2574-7762.000033$

17. Yeudall LT, Fromm-Auch D, Davies P (1982) Neuropsychological Impairment of Persistent Delinquency. The journal of Nervous and Mental Disease 170: 257-265.

18. Miczak HA (1987) Psychopharmacology of aggression. In LL Iversen, SD Iversen \& SH Snyder (Eds.) Handbook of Psychopharmacology 19: 235-77. New York: Plenum Press.

19. Busch KG, Zagar R, Hughes JR (1990) Adolescents who kill. J Clin Psychol 46: 472-484.

20. Dalteg A, Lindgren M, Levander S (1999) Retrospectively rated ADHD is linked to specific personality characteristics and deviant alcohol reactions. The Journal of Forensic Psychiatry 10: 623-634.

21. National Report, SOU, 1954:5. Ungdomsvårdsskoleutredningen: "Vården vid ungdomsvårdsskolorna."(The Borstal Schools). Stockholm: Socialdepartementet.

22. National Report, SOU, 1964: 24. Behandlingsforskning vid ungdomsvårdsskolorna (Treatment research at Borstal schools). Stockholm: Socialdepartementet.

23. Gordan K, Näs NO (1969) En undersökning av 1964 års Ungdomsvårdsskoleelever. (The Borstal subjects of 1964) Socialstyrelsen redovisar nr. 6 1969. Stockholm: Socialstyrelsen.

24. Dalteg A, Levander S (1998) Twelve Thousand crimes by 75 boys: a 20-year follow-up study of childhood hyperactivity. The Journal of Forensic Psychiatry 9: 39-57.

25. Hare RD (1991) The Hare Psychopathy Checklist - Revised, Toronto, Ontario: Multi-Health systems.

26. Mattsson Å, Schalling D, Olweus D, Löw H, Svensson J (1980) Plasma Testosterone, Aggressive Behaviour and Personality Dimensions in Young Male delinquents. Journal of the American Academy of Child Psychiatry 19: 476-490.

27. Levander S, Mattsson Å, Schalling D, Dalteg A (1987) Psychoendocrine patterns within a group of male juvenile delinquents as related to early psychosocial stress, diagnostic classification and follow-up data. In Magnusson, D \& Öhman, A (Eds). Psychopathology: An Interactional Perspective, 1987. London: Academic Press.

28. Widom C (2000) Motivation and mechanisms in the 'Cycle of Violence'. Nebraska Symposium on Motivation 46: 1-37.

29. Schote AB, Bonenberger M, Pálmason H, Seitz C, Meyer J, et al. (2016) Glucocorticoid receptor variants in childhood attention-deficit/ hyperactivity disorder and comorbid psychiatric disorders. Psychiatry Res 246: 275-283.

30. Torok M, Darke S, Shand F, Kaye S (2016) Investigating heterogeneity in violent offending liability among injection drug users from a developmental perspective. Addict Behav 60: 165-170.

31. Morris H, Escoll P, Wexler R (1956) Aggressive Behaviour Disorders of Childhood: A Follow-up Study. American Journal of Psychiatry 112 991-997.

32. Barker ED, Tremblay RE, van Lier PA, Vitaro F, Nagin DS, et al. (2011) The neurocognition of conduct disorder behaviors: specificity to physical aggression and theft after controlling for ADHD symptoms. Aggress Behav 37: 63-72.
33. Nilsson T, Falk Ö, Billstedt E, Kerekes N, Anckarsäter H, et al. (2016) Aggressive Antisocial Behaviors are related to Character Maturity in Young Swedish Violent Offenders independent of ADHD. Front Psychiatry 16: 185-194.

34. Dalteg A, Zandelin A, Tuninger E, Levander S (2014) Psychosis in adulthood is associated with high rates of $A D H D$ and $C D$ problems during childhood. Nord J Psychiatry 68: 560-566.

35. Conners CK, Epstein JN, March JS (2001) Multimodal treatment of ADHD (The MTA project). Journal of the American Academy of Child and Adolescent Psychiatry 42: 134-249.

36. Dalteg A (1990) Avancerade unga lagöverträdare. In Swedish with an English summary: Advanced Juvenile delinquents. PhD thesis. Research Reports from the Department of Psychiatry and Behavioural Medicine, University of Trondheim, No. 75.

37. Torstensson M (1987) Drug Abusers in a Metropolitan Cohort. PhD thesis. Project Metropolitan Research Report No 25. Department of Sociology, Stockholm University.

38. Nilsson A, Estrada F (2009) A longitudinal study of crime, childhood circumstances and living conditions up to age 48. Report: 3, Department of Criminology Report Series, Stockholm University.

39. Elonheimo, Sillanmäki, Sourander (2015) Crime and mortality in a population-based nationwide 1981 birth cohort: Results from the FinnCrime study. Crim Behav Ment Health 25: 15-26.

40. Teplin L, McClelland GM, Abram KM, Mileusnic D (2005) Early violent death among delinquent youth: a prospective longitudinal study. Pediatrics 115: 1586-1593.

41. Fazel S, Wolf A, Fimińska Z, Larsson H (2016) Mortality, Rehospitalisation and Violent Crime in Forensic Psychiatric Patients Discharged from Hospital: Rates and Risk Factors. PLoS One 11: e0155906.

42. Nilsson LL, Lögdberg B, Levander S (2017) Early death among 151 patients diagnosed with schizophrenia - a 20 year follow-up study. (Submitted, Acta Psychiatrica Scandinavia).

43. Scott JG, Giørtz Pedersen M, Erskine HE, Bikic A, Demontis D, et al. (2017) Mortality in individuals with disruptive behavior disorders diagnosed by specialist services - A nationwide cohort study. Psychiatry Res 251: 255-260.

44. Rosell DR, Siever LJ (2015) The neurobiology of aggression and violence. CNS Spectr 20: 254-279.

45. Erskine HE, Norman RE, Ferrari AJ, Chan GC, Copeland WE, et al. (2016) Long-Term Outcomes of Attention-Deficit/Hyperactivity Disorder and Conduct Disorder: A Systematic Review and Meta-Analysis. J Am Acad Child Adolesc Psychiatry 55: 841-850.

46. Sharp AL, Prosser LA, Walton M, Blow FC, Chermack ST, et al. (2014) Cost analysis of youth violence prevention. Pediatrics 133: 448-453. 